\title{
EDUCATION AS A FACTOR OF EMPLOYMENT AND INCOME
}

\author{
LALI KHURTSIA \\ Doctor of Economic Sciences, assistant Professor \\ Ivane Javakhishvili Tbilisi State University, Georgia \\ lali.khurtsia@tsu.ge
}

\section{GIORGI GAPRINDASHVILI}

Academic Doctor of Economic Sciences, assistant Professor

Ivane Javakhishvili Tbilisi State University, Georgia

giorgi.gaprindashvili@tsu.ge

\section{KEYWORDS: EDUCATION, EMPLOYMENT, SALARY, HUMAN CAPITAL}

Economic trends in recent years clearly indicate a relatively new phenomenon that can be called the economy of knowledge. Obviously, the main driving force of modern economic progress has become a human, who represents the subject of accumulation of knowledge reflected in capital.

Periodically, mass media are displaying the list of the world's richest people, who have accumulated wealth in their lives, not inherited. The press also circulates the information about the fantastic honorarium of individual persons who receive them through working in various fields. What are the causes and what is the success of these people based on? The thing is that, the person has become the basis for his own success and this success is no longer dependent on heritage, genealogy or other conditions. The defining factor of this success is the competitive knowledge that a man acquires throughout his lifetime. (Gaprindashvili \& Parhjiani, 2018)(Kavtidze, 2012).

The modern global culture, based on the principles of liberal democratic ideology and free market relations, clearly expresses the aspiration towards the human rights' equality. Implementation of such postulates was difficult in historically non-free societies where human rights were defined by their hereditary, racial or religious affiliation. Nowadays, in the countries, where the principles of freedom are recognized, every single person is born to be equal in the fight for the detention of the social status, in the fight whose economic interpretation implies permanent struggle of a human as a customer to ensure maximum income to meet own needs throughout life.

In this battle, which Thomas Hobs called "War of All Against All", the different methods were used to succeed in different times, that were influenced by the dominant ideology of that specific historic moment of the epoch. Competitive knowledge has become a precondition for success in modern life that cannot be compared with any sector of the economy with regard to the quality of competition, based on the total number of world population.

If in the early epochs, it was enough to specialize in any manual work, for instance be a tailor or a shoemaker and satisfy personal needs as well as family needs throughout the life, https://doi.org/10.35945/gb.2018.06.024 nowadays, quickly changing technological processes, demand that periodically a person's qualification has to be improved as of the main factor of production.

The economy of knowledge has a profound impact on the economic success of the state. In the early economic relations, the welfare of the state was determined by the extensive type of production, while from the late Middle Ages, the basis of the economic success has become reducing production price, based on the introduction of new technologies. Consequently, a man as a knowledge factory has become a generator and inspiring of new technologies and innovative ideas. If we refer to neoclassical theory, economic growth is the result of the accumulation of capital and growth of workforce together with the introduction of technological processes that reduce production costs. Considering the economy of knowledge, economic growth has become dependent on human factors that participate in manufacturing processes as a continuous renewable knowledge capital. The higher and the newer accumulated knowledge is and the more relevant it is to the market requirements the higher the value of human knowledge becomes, measured in capital (Khurtsia\&Tsertsvadze, 2008).

Education is an investment nature goods that people are trying to accumulate in the form of human capital with the expectation to receive income in the future. Econometric studies provide strongly consistent evidence that more educated workers are more productive and they receive higher salaries than the workforce who lack the education (Psacharopoulos\&Patrinos, 2004). People try to make investments at a young age to increase their capabilities, i.e. to accumulate human capital at a young age, which is caused by the life cycle of income. As a result of the observation, income is lower in youth, and its growth is further after the investment level on oneself is reduced and realization of already implemented returns is taking place. Individuals are trying to collect human capital in order to get higher income (Becker S., 1962) (Mincer, 1958).

Becker also embodies the peak-age with regard to receiving income between educated and uneducated people. 
In the course of life, with the increase in age, the amount of acceptable compensation also changes when a person is inexperienced and young, the level of getting income is less than in the middle of life. The average income peak age is 45 to 54 years and then it begins to decrease with the increase of age. In case of unqualified staff, preference is given to adolescents, as for adults with the increase in age, the demand on them decreases, which occurs much late in case of educated people, so peak age for unskilled personnel is earlier than for qualified workers (Becker, 1964).

It is noteworthy that a man with a small human capital, with the hope of more profit, refuses to earn a lower income to accumulate more human capital and thus increase the income (Mankiw, David, \& Weil, 1992).

Human capital, like physical capital, is the subject to depreciation. But here we are dealing with the loss of knowledge (outdated), as well as the physical and spiritual weakening of the knowledgeable person. The same type of investment in physical capital in case of other equal terms equals in income, while the two people who have received the education in the equal conditions achieve significantly different results. The reason for this is the difference in human intellectual capabilities, natural characteristics and environmental conditions. More specifically, the physical and spiritual strengths of a person as knowledge capital depends on many social factors
- health, culture and leisure, nutrition levels. Therefore, in addition to investments made in the field of education, it is necessary to pay attention to the funding of healthcare, which will inevitably reflect on the improvement of the labor productivity and the increase in the production effectiveness.

The trend of education, employment and income in Georgia is similar to trends in developed countries. For comparison, we have presented here the data of Georgia and US. In the case of Georgia we have used CRRC 2017 research data: the income earned per month, the highest level of respondent education and employment/unemployment rates. The data is shown in the diagram below, which shows that people standing at higher levels of education precede others with average income and better employment rates.

It is obvious that the returns received from specialized higher education are higher than in case of the average secondary education. In the second picture the income of people with qualified degree precedes the income of people with all other categories. Production benefits derived from a qualified financial analyst's or neurobiologist work are higher than those of the general education economists or Doctor of medicine's work. Nevertheless, it should be noted that any form of education helps to meet the demands of the labor market and provide it with the personnel with relevant skills that are useful in the workplace. It would seem that if everybody

Avarage monthly income and unemployment acoording the level of education (Georgia)

$-20 \%$

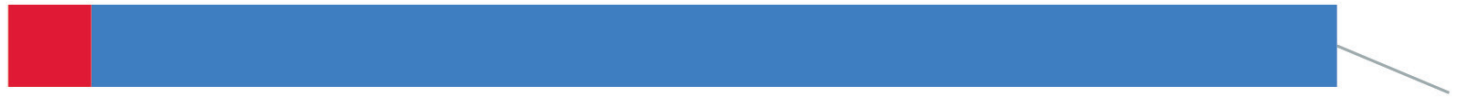

Higher Education $\$ 300$

$-24 \%$

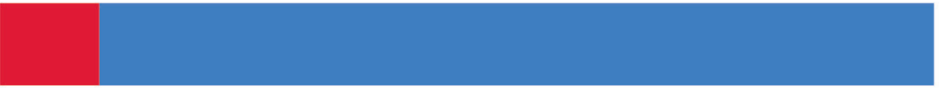

Vocational Education, $\$ 201$

$-26 \%$

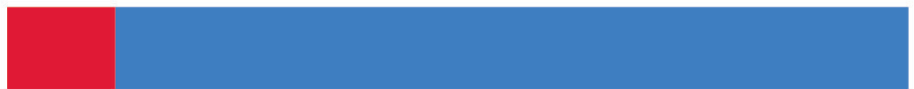

Basic Education, \$191

- unemployed - income

Figure 1 the graph is created through the Caucasus Recourse Research Center (CRRC) Online Data Analysis (ODA) Program, based on data of 2017 (http://crrc.ge, http://caucasusbarometer.org/en/)

The figure below shows the same data in US. The data are broken down in detail and clearly describe differences caused by education between the different rates in income and employment. 
Avarage weekly income and unemployment according the level of education (USA)

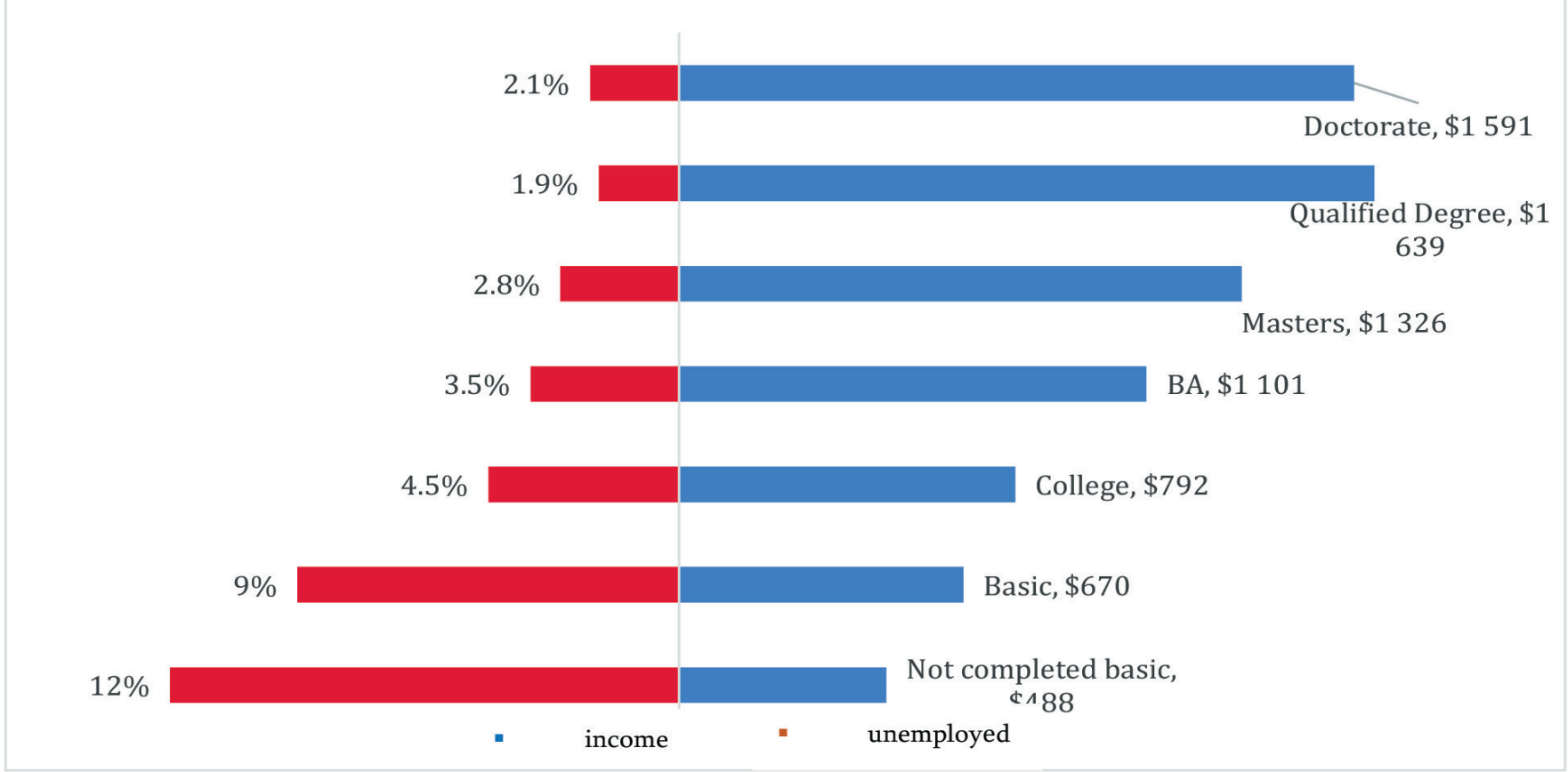

Figure 2 data is used from Beuro of labor Statistics of US, report 2014. The data reflect income and unemployment after the age of 25 (https://www.bls.gov).

gains the higher education level, it will create a shortfall in the unskilled labor market, but in the modern information technology era, innovations are the most important factor in increasing productivity and are being created to replace people in daily routine activities. Thus the choice of a person on the level of education places the low level of qualification outside of choice. Accordingly, basic education package that includes basic literacy (writing/reading, communication and mathematics) acquired during school education is a non-alternative cost that enables a choice in the future in favor of professional training or raising qualification. The amount paid today in the development of basic skills will give us an increased number of highly qualified people in the form of return and their ability to effectively introduce and use new technologies.

\section{REFERENCES:}

1. Becker S., G. (1962). Investment in Human Capital: A theoretical analysis. Journal of Political Economy, 9-49.

2. Becker, G. (1964). Human Capital: A Theoretical and Empirical Analysis, with Special Reference to Education. Columbia University Press, New York.

3. Gaprindashvili, G., \& Parhjiani, S. (2018). Georgia in interanational ratings and main trends of economic policy. Economics, \#2-3, 17-37.

4. Kavtidze, E. (2012). How income and quality of life influence labor supply. Social economcs \#4 2012, 82.

5. Khurtsia, L., \& Tsertsvadze, V. (2016 ). Cultural and historical roots of plagiarism in Georgia, . International scholarly and scientific research \& inovation elSSN:2010-3778, 1931-1934.

6. Khurtsia, L., Tsertsvadze, V., \& Krilova, Y. (2017). Student plagiarism in Georgia's higher education . Ongoing Issues in Georgian Policy and Public Administration, Washington D.C.

7. Mankiw, G. N., David, R., \& Weil, D. N. (1992). A Contribution to the Empirics of Economic Growth. Quarterly Journal of Economics, 416-437.

8. Mincer, J. (1958). Investment in Human Capital and Personal Income Distribution. The journal of political Economy, vol. LXVI, 282-302.

9. Psacharopoulos, G., \& Patrinos, H. (2004). Returns to Investment in Education: A Further Update. Education Economics, vol. 12, No. 2, 112-134. 


\section{EDUCATION AS A FACTOR OF EMPLOYMENT AND INCOME}

\section{LALI KHURTSIA}

Doctor of Economic Sciences, assistant Professor

Ivane Javakhishvili Tbilisi State University, Georgia

lali.khurtsia@tsu.ge

\section{GIORGI GAPRINDASHVILI}

Academic Doctor of Economic Sciences, assistant Professor

Ivane Javakhishvili Tbilisi State University, Georgia

giorgi.gaprindashvili@tsu.ge

KEYWORDS: EDUCATION, EMPLOYMENT, SALARY, HUMAN CAPITAL

\section{SUMMARY}

The article deals with the analysis of the education role with regard to the impact on income and employment. To identify the link between education and unemployment, and education and income, CRRC secondary data is used. According to the analysis, the alternative cost for basic education is important, which allows the increased number of highly qualified staff and high quality of work efficiency in the future. 